\title{
Coastal Monitoring: A New Approach
}

\section{A New Approach}

\author{
Sarah M. Kandrot \\ Geography Department, University College Cork
}

Monitoring changes in the morphology of coastal environments is important for understanding how they function as systems and how they can be most effectively managed to offer maximum protection of the coastal hinterland. The quick, precise, and efficient method of topographic data capture associated with a remote sensing (RS) technology called terrestrial laser scanning (TLS), also known as ground-based Light Detection and Ranging (LiDAR), facilitates improved monitoring of morphological changes to coastal environments over traditional survey methods. Terrestrial laser scanning systems are capable of providing extremely detailed 3-dimensional topographic information in the form of a "point cloud" - a densely packed collection of $x, y, z$ coordinates that collectively represent the external surface (often the ground) of a surveyed area. Such detailed elevation information is useful for coastal research, resource management and planning, hazard and risk assessment, and evaluating the impacts of climate change and sea-level rise on the coast. This paper introduces TLS and its applications in a coastal setting and addresses some of the challenges associated with its use as a monitoring tool in vegetated coastal dune environments. Such challenges include optimising time spent in the field, working with large datasets, classifying simple and complex scenes, and analysing multi-temporal datasets.

Keywords: coastal monitoring, terrestrial laser scanning, coastal sand dunes

\section{Introduction}

Coasts are perhaps the most active of all geomorphic environments, and learning how to adapt to this dynamism will be the first global challenge that we, as a society, will face as a result of climate change. Already coasts are experiencing the adverse consequences of hazards related to a warming climate and rising sea-level, including increased incidences of extreme storm events and increased coastal erosion (Meehl et al., 2007; Parry et al., 2007; Trenberth et al., 2007). In the US alone, coastal erosion is responsible for approximately $\$ 500$ million per year in coastal property loss (Rabenhold, 2012). Coastal research is now more relevant than ever.

One important way in which coastal researchers study the coast is through morphological monitoring - the repeated collection of information about the topography of the submarine, intertidal, and terrestrial land surface. Traditional methods of monitoring coastal change have typically relied on low-quality, and often sparse, datasets, such as aerial photographs, historic maps, and beach profiles. Studies based on two dimensional cross-shore profiles, however, completely ignore the mechanisms by which beaches function in the third dimension (perpendicular and, especially, oblique to the cross-shore profile). In the case of aerial photographs and historic maps, while they may afford a greater coverage area, the information provided is at a lower spatial resolution (ie. it is less detailed) and may only be available at infrequent and irregular intervals.

Light Detection and Ranging, or LiDAR, technology, however, allows for much improved monitoring of coastal morphological change through the provision of three dimensional topographic datasets at spatial and temporal scales that were, until recently, unattainable. Its development has had major implications for coastal research and resource management and planning, with researchers having quickly identified a variety of applications for LiDAR remote sensing (Brock and Purkis, 2009). Such applications include using LiDAR datasets to quantify beach-dune morphological change (Ali et al., 2011; Feagin et al., 2012), to monitor sea cliff erosion (Lim et al., 2005; Rosser et al., 2005), to study Aeolian (or wind-driven) sediment transport (Lindenbergh et al., 2011; Nield and Wiggs, 2011; Nield 
et al., 2011), and to evaluate the vulnerability of low-lying coastal regions to flooding caused by relative sea-level rise (Gesch, 2009).

While LiDAR is seen as a "remarkable new asset" (Brock and Purkis, 2009, p. 1) to coastal researchers, its use as a morphological monitoring tool is an application still in the early stages. Significant challenges in this area remain, especially in terms of establishing methodologies and best practice standards for collecting and analysing groundbased LiDAR data. This paper will provide some background information on ground-based LiDAR (more commonly known as terrestrial laser scanning, or TLS) and its applications in a coastal setting. It will also provide a first-hand account of the challenges associated with using TLS as a morphological monitoring tool in a vegetated dune environment based on experiences from on-going research in Dingle Bay, Co. Kerry, Ireland.

\section{Terrestrial Laser Scanning: Principles and Applications}

Terrestrial laser scanning technology is used to collect extremely detailed 3D information about a surface. TLS sensors use LiDAR, an active RS technology that uses either a reflected laser pulse or, less commonly, differences in phase from a continuous beam, to measure the distance to an object (often the ground surface). Pulse-based sensors sweep millions of laser pulses across a surface and use the time it takes for those pulses to be reflected back to the instrument to measure the distance to the surface. There are two basic types of LiDAR sensors - airborne (fig. 1) and ground-based (fig. 2). Airborne systems are flown on an aircraft, and thus are capable of capturing data over a relatively wide area. They consist of three main parts: the sensor, the inertial measurement unit (IMU), and the global positioning system (GPS) which work together to produce georeferenced topographic data. Ground-based LIDAR sensors, or Terrestrial Laser Scanners (TLS), capture data from a (or, most commonly, several) fixed position(s) on the ground. Georeferencing is usually established through the use of a known benchmark, although newer models may have a built-in GPS and altimeter. The result of a LIDAR survey, airborne or ground-based, is millions of densely-packed 3-D points, each with a unique xyz coordinate, collectively known as a point cloud (fig. 3 and fig. 4). Information about the intensity, or strength of the reflected laser pulse, is also collected. In the examples shown in figure 3 and figure 4, points were measured with positional accuracy of $6 \mathrm{~mm}$ at a resolution of approximately $1 \mathrm{~cm}$.

For the study of micro-scale morphologic change (anything less than $<0.5 \mathrm{~m}$ ), ground-based LiDAR is especially useful. Terrestrial laser scanners provide a far greater point density ( $>3$ orders of magnitude) than airborne LIDAR, thus facilitating more complete capture of the spatial heterogeneity of a surface and making them ideal tools for the study of micro-scale morphological features (eg. Nagihara et al., 2004; Dunning et al., 2009) and processes (eg. Travelletti et al., 2008; Lindenbergh et al., 2011; Nield and Wiggs, 2011). Ground based laser scanners can be deployed for immediate data collection, and they are therefore more practical for performing multiple surveys over relatively short time periods. This is especially important in fast changing environments, such as on beaches, where near instantaneous events can result in large morphological changes (Lindenbergh et al., 2011). 


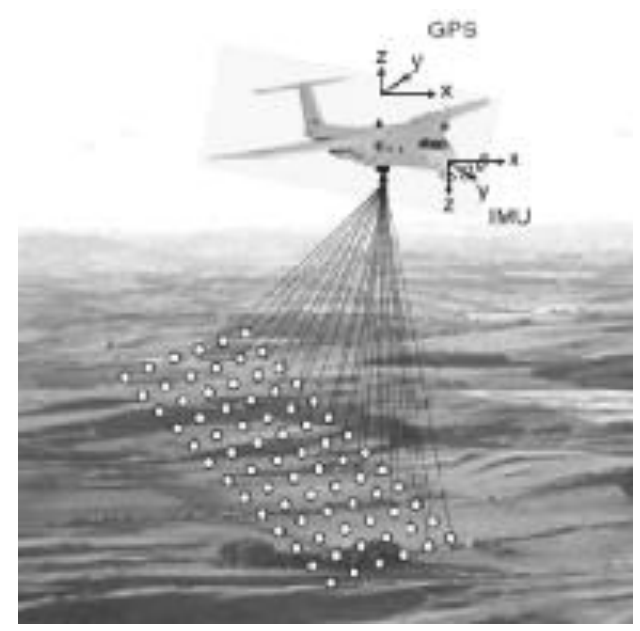

Figure 1 Airborne LiDAR system. Points on the surface represent the points at which the laser is reflected back to the instrument. Extracted from Heritage and Large (2009)

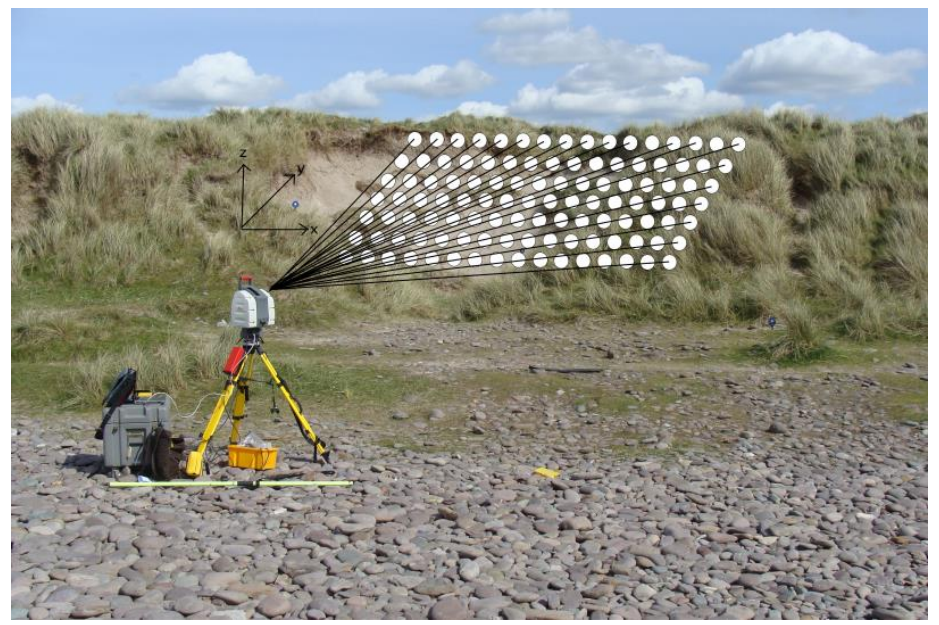

Figure 2 Ground-based LiDAR system. More commonly known as Terrestrial Laser Scanning (TLS). Points on the surface represent the points at which the laser is reflected back to the instrument

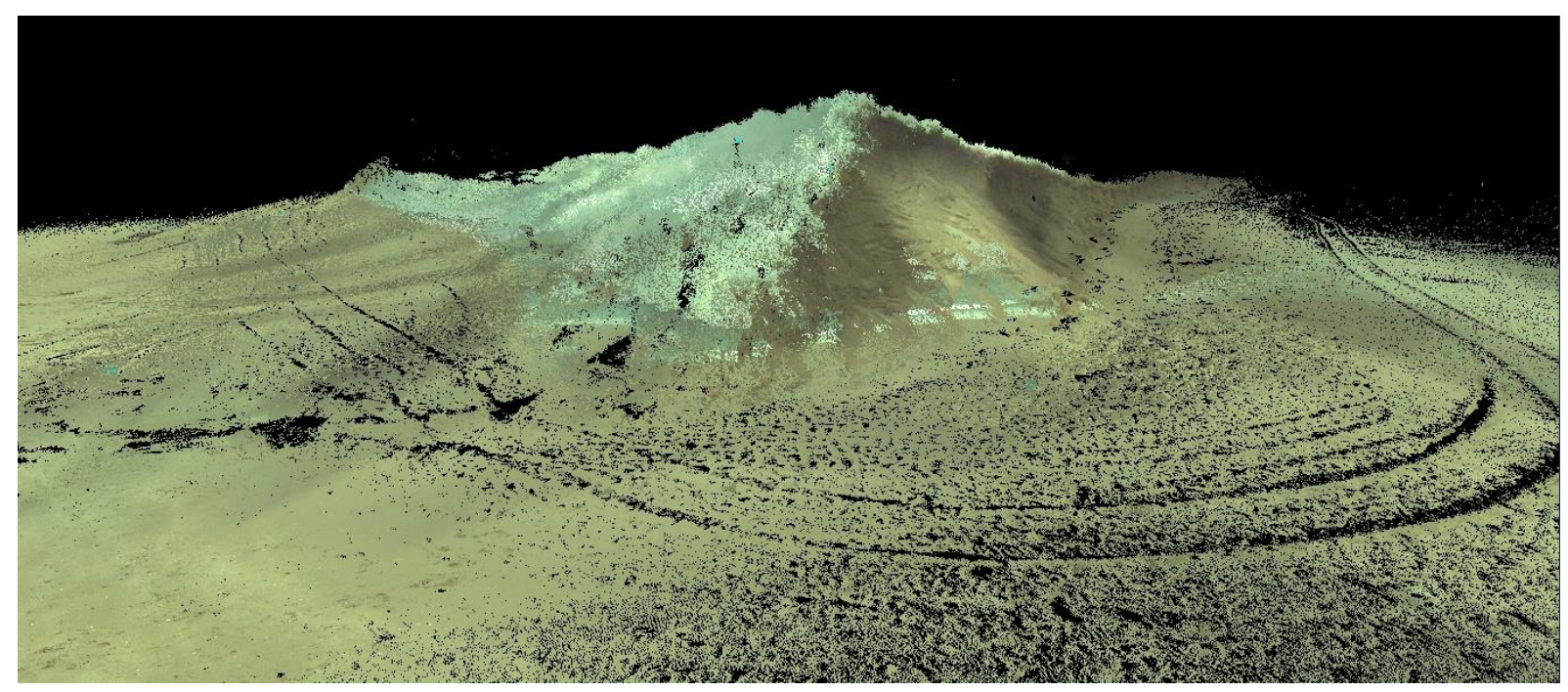

Figure 3 Colour-rendered TLS point cloud showing coastal sand dunes at Rossbeigh, Co. Kerry, Ireland. The scan is so detailed, that the tyre marks from the cart used to transport the equipment to and from the site can easily be identified 


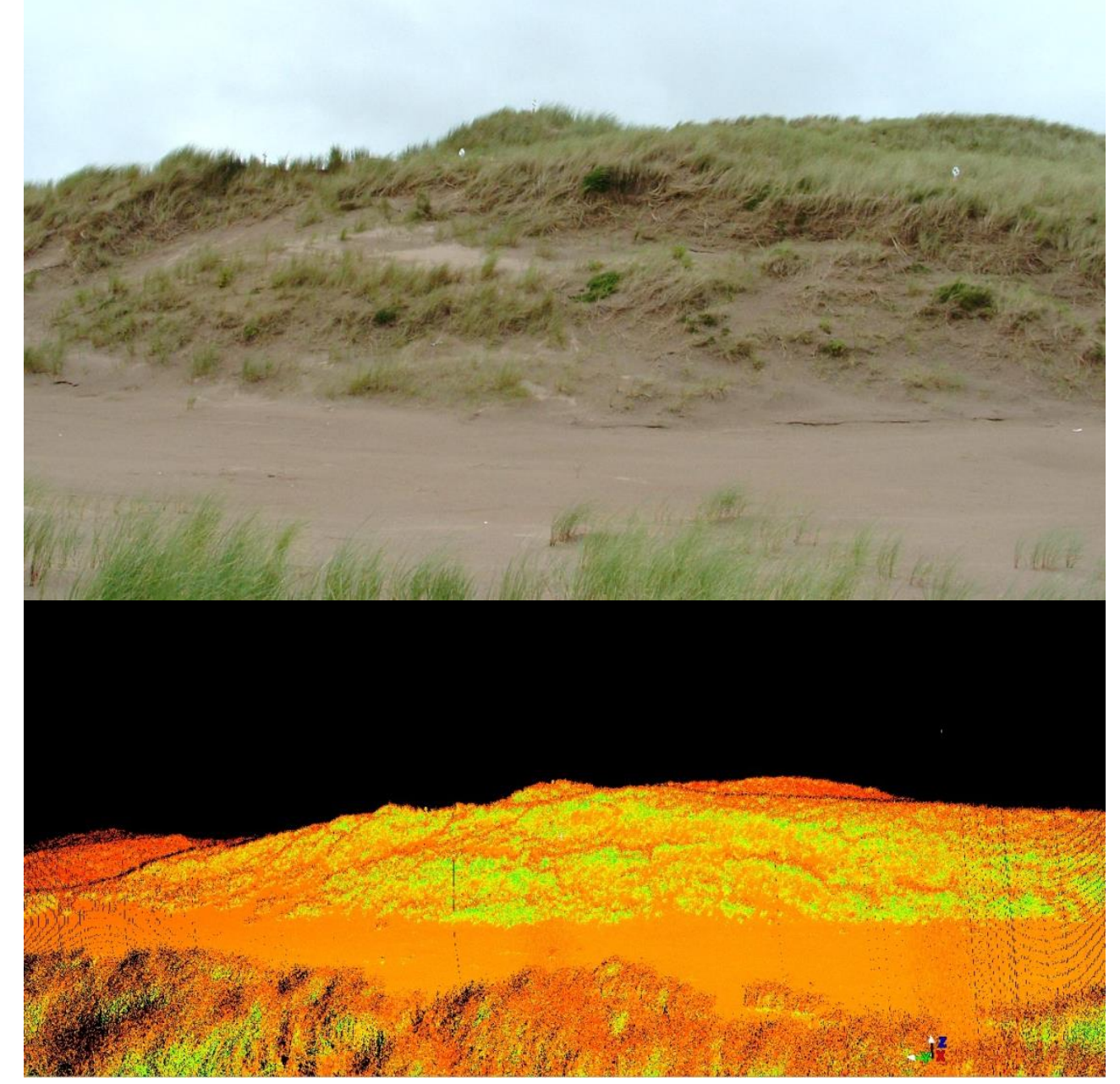

Figure 4 (Top) Photo of study area where (bottom) TLS point cloud was surveyed at coastal dunes at Inch, Co. Kerry. Unlike the colour-rendered cloud above, this cloud is coloured using reflected laser intensity values.

Despite its advantages over aerial LiDAR, the use of TLS in coastal environments is heavily underrepresented in the literature. Only a handful of studies in this area have been published in the last decade, many of which have been published only in the last two years. These studies fall into three main categories - TLS as a tool for studying (1) beach-dune morphological change, (2) Aeolian sediment transport and (3) sea cliff erosion.

Recent work by Ali et al. (2011), van Gaalen et al. (2011), Feagin et al. (2012) and others (Soeder and Jenkins, 2006; Pietro et al., 2008) demonstrates the usefulness of TLS as a tool for studying beach-dune morphological change. In a paper presented recently at an annual meeting of the Geological Society of America, Ali et al. (2011) describe how they supplemented airborne LiDAR data with TLS data to provide more detailed information about erosion hotspots on Galveston Island (Texas, USA). The precise and accurate identification of erosion hotspots is essential for coastal hazard mapping and allows coastal planners and administrators to make more informed management decisions (Coyne et al., 1999). Results of this research, however, were preliminary and remain unpublished.

In another recent study, this time published in the journal Geomorphology, van Gaalen et al. (2011) coupled TLS survey data with sedimentological and hydrodynamic data. This technique allowed them, for the first time, to explain varying depositional and erosional trends of beach cusp evolution. An understanding of this type of microscale landform development is important for better understanding larger scale beach processes. 
At all morphological scales, hurricanes can have a major impact on beach-dune morphology, but the impacts may be difficult to quantify at the micro- to meso-scale. Recognising the shortcomings of traditional monitoring techniques at these scales, Feagin et al. (2012) used TLS to investigate changes in sediment and vegetation volumes on the East Matagorda Peninsula (Texas, USA) after Hurricane Ike (2008). While they demonstrated the ease at which changes in sediment and vegetation volume could be calculated from TLS datasets, an evaluation of the error associated with their methods was lacking (see section 3).

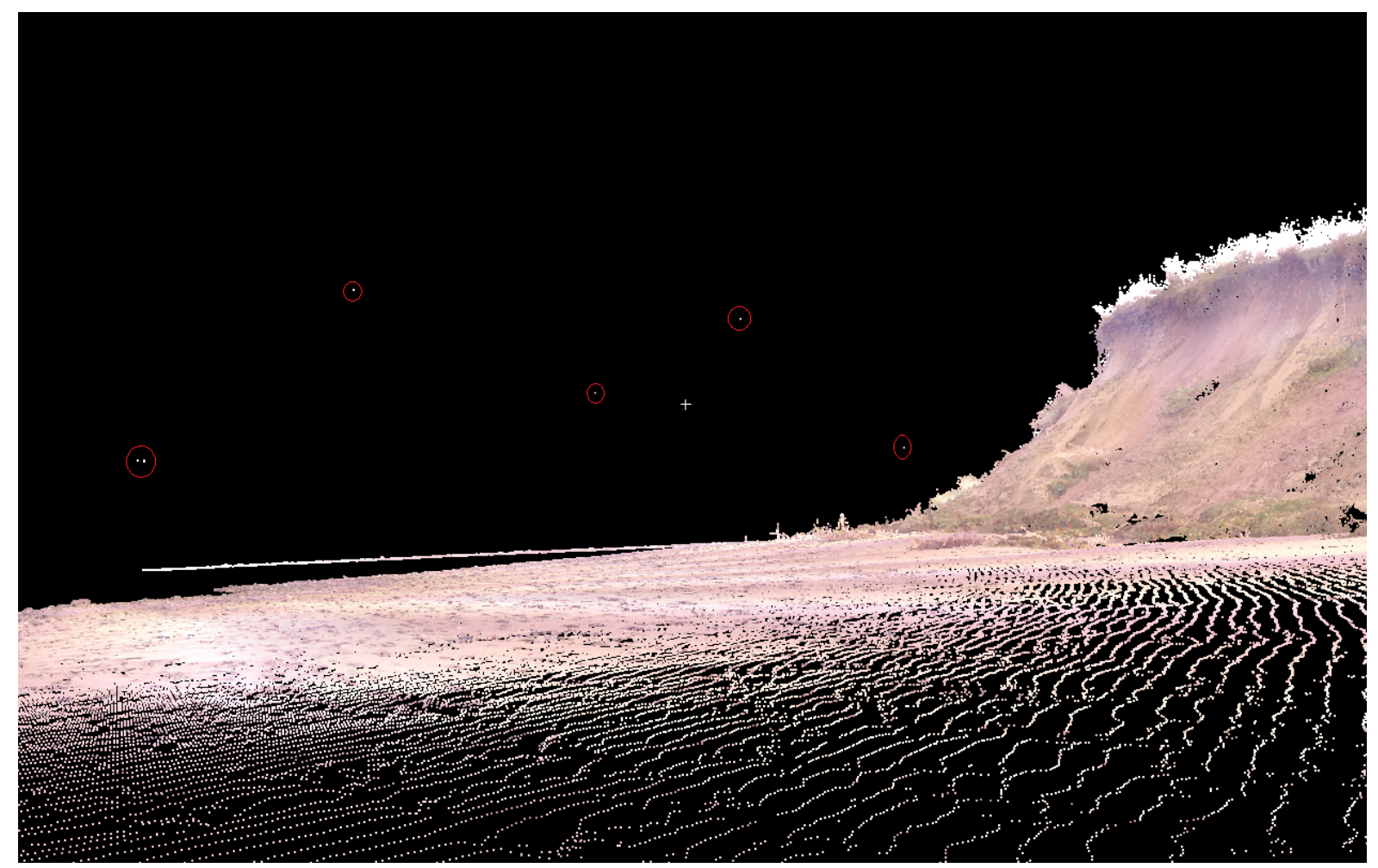

Figure 5 Commonly thought of as erroneous data, these non-surface points (circled) are suspended sand grains and give an indication of saltation cloud characteristics.

Alongside morphodynamic research, Aeolian research has also benefitted from TLS. Aeolian research involves the study of wind-driven sediment transport and is important for understanding sedimentary landform formation and development. Experimental approaches in Aeolian research have always been unique and innovative due to the difficulty associated with studying small, suspended, moving particles. Various experiments have been recently conducted using TLS. For example Lindenbergh et al. (2011) and Nield et al. (2011) were able, for the first time, to study the effects of varying weather conditions on millimetre-scale landform development. Another innovative study (Nield and Wiggs, 2011) took advantage of TLS data that would ordinarily be considered erroneous to study Aeolian saltation cloud characteristics. A saltation cloud is a collection of suspended sand grains in motion. In the past, examining active transport of suspended sediment particles had been limited by the instrumentation available. However, terrestrial laser scanners are capable of detecting such particles. Suspended particles often appear in point clouds as apparently random non-surface points (fig. 5). Nield and Wiggs (2011) used this to their advantage and demonstrated the importance of saltation in the development of protodunes on a drying beach. 


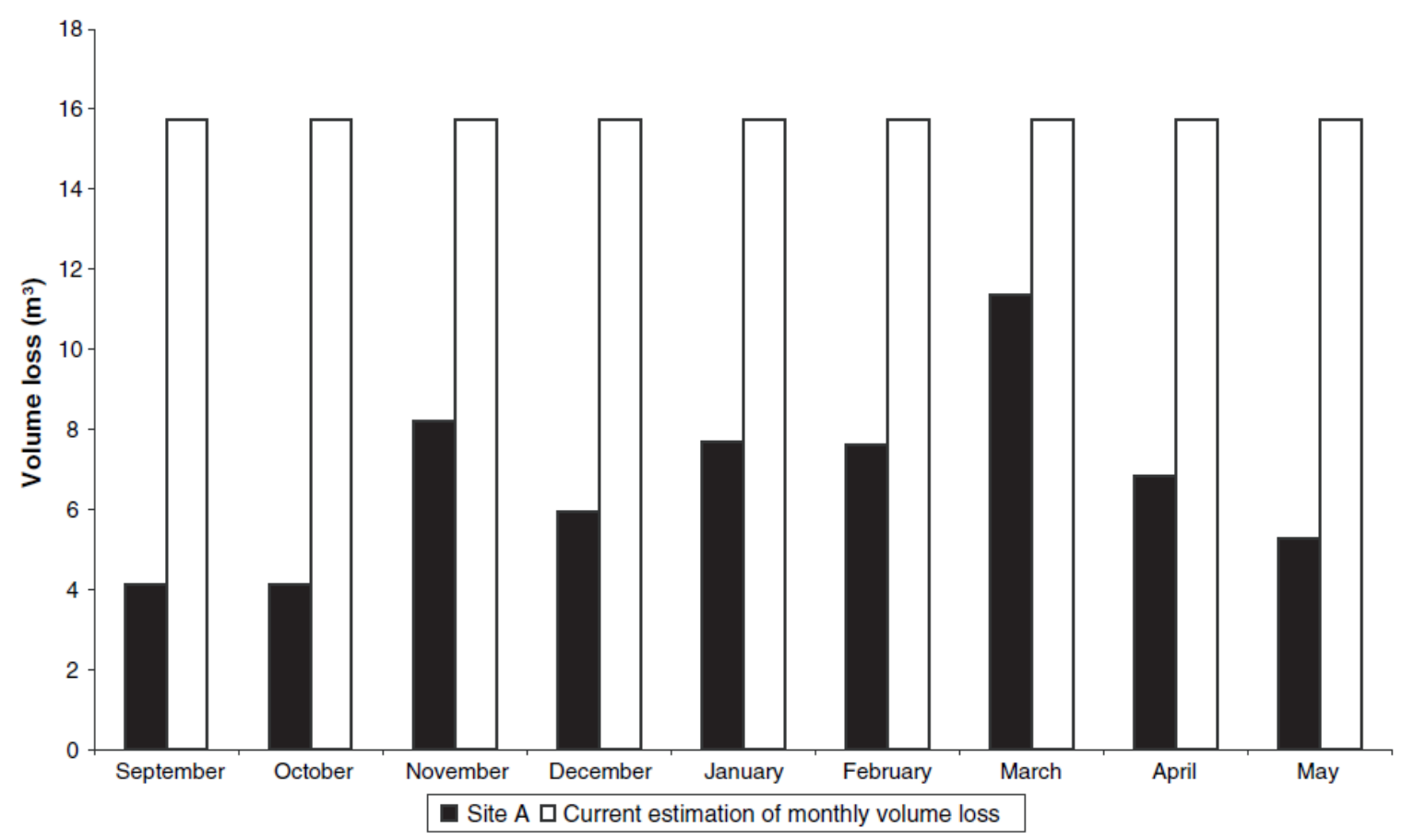

Figure 6 Predicted volumetric losses (white) versus observed losses (black) of a sea cliff face reported by Lim et al. (2005). Predicted losses represent average rates of sea cliff recession inferred from aerial photos, while observed losses were recorded using TLS. Extracted from Lim et al. (2005).

Other studies (Lim et al., 2005; Rosser et al., 2005; Olsen, 2009) have made use of TLS to study sea cliff erosion. Terrestrial laser scanned datasets have led to significant improvements in understanding of the activity patterns of coastal cliffs. These datasets have allowed researchers to identify direct mechanisms of cliff failure that were previously unidentifiable using traditional cliff survey techniques (ie. using aerial photos and historic maps). For example, Rosser et al. (2005) compared spatial variations in sea cliff recession from TLS datasets to those inferred from conventional techniques and found that the commonly used approach of using average cliff recession rate was grossly under representative of coastal cliff development. Similarly, Lim et al. (2005) found significant disparities between predicted sea cliff recession rates from aerial photos and those observed using TLS datasets (fig. 6). This has serious implications for current management practices that rely on traditional monitoring techniques.

These early studies underscore the vast potential of TLS in coastal research. Although quoted with reference to airborne LiDAR, a statement made by Brock and Purkis (2009) equally sums up the future of terrestrial LiDAR:

The resolution of modern LiDAR systems is sufficient to address long standing questions regarding coastal geologic, hydrologic, and biologic processes, and provide morphological observations that are leading to a better understanding of coastal landscape change over time (Brock and Purkis, 2009, p. 4).

\section{Using TLS for Monitoring Dune Morphodynamics: Lessons Learned in Dingle Bay}

While TLS undeniably has great potential in coastal research, significant progress remains to be made in terms of standardisation of control practices and error assessments (Buckley et al., 2008; Heritage and Large, 2009). Best practice standards are yet to be established, although discussions of methodological and quality control issues in various contexts have begun (eg. Lichti et al., 2005; Buckley et al., 2008; Soudarissanane et al., 2011). Presently, it is up to the user to develop a methodology that meets the specific requirements of the research being undertaken. While guidelines from recently published literature exist, often they lack adequate advice with regard to a number of issues. These issues are addressed here based on experiences from on-going research on dune morphodynamics in Dingle Bay, Co. Kerry, Ireland. This research involves monitoring small- to medium- scale changes in the morphology 
of coastal foredunes using terrestrial laser scanning and later attempting to explain these changes in terms of their (potential) relationship to climate and sea-level.

\subsection{Optimising time spent in the field}

The first challenge associated with TLS surveying is balancing various parameters to optimise time spent in the field. This means making decisions with regard to the number of scans to be obtained, scan resolution, and coverage area. It also means adequately familiarising one's self with the instrument being used (practice, practice, practice!) so as not to be wasting valuable time in the field.

Often it is necessary to complete more than one scan from different angles to avoid having too many shadow areas, or zones of missing data located behind some obstruction to the scanners field of view (fig. 7). The number of and positions of scans required to minimise shadowing should be considered during early reconnaissance visits to the site.

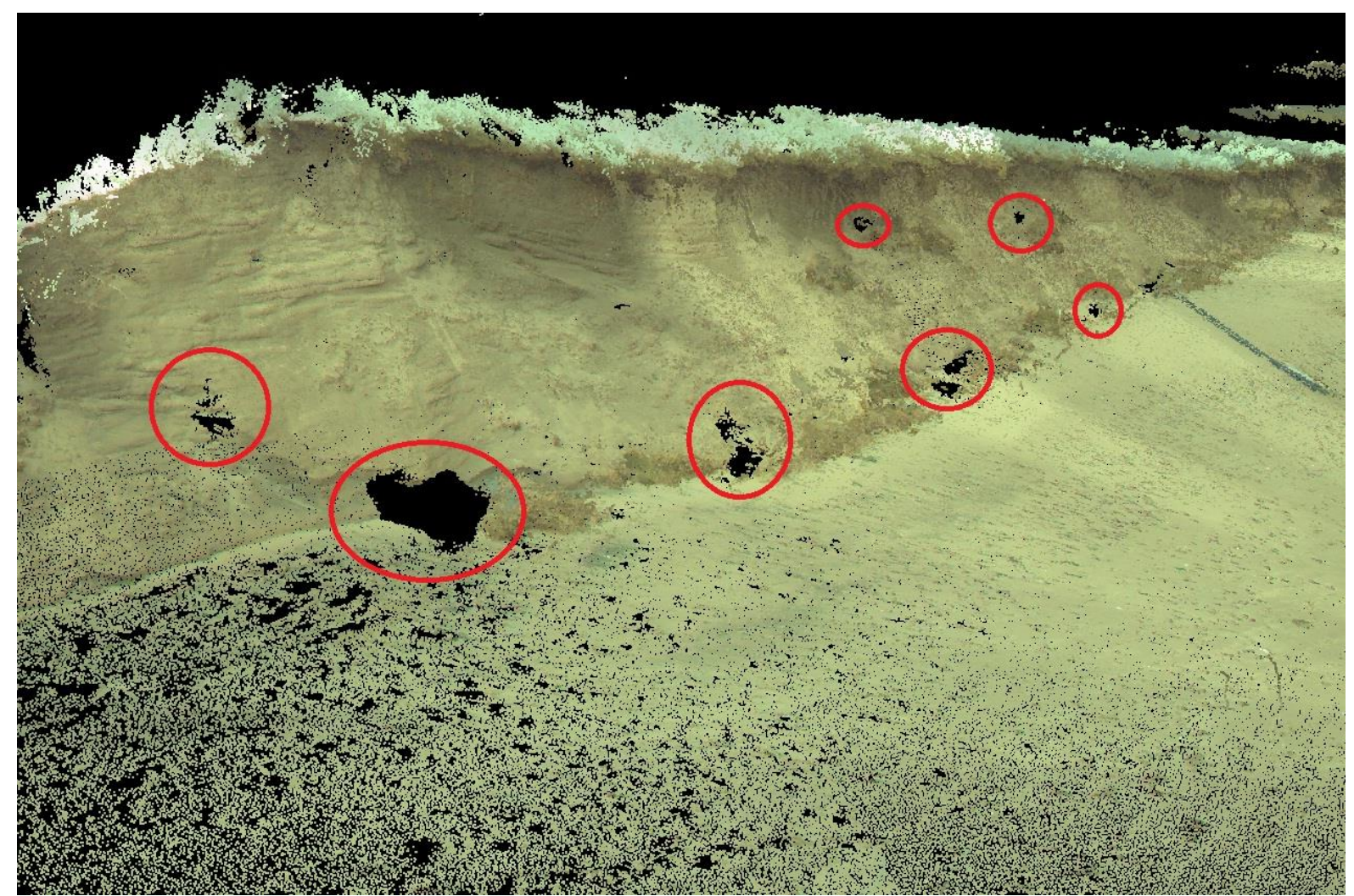

Figure 7 Shadow areas, zones of missing data located behind some obstruction to the scanners field of view, can be minimised by scanning from more than one angle.

Scan resolution and coverage area must also be considered. These factors depend on the speed of the instrument being used. While TLS instruments are rapidly evolving and data capture is becoming ever faster, the cost of keeping up to date may be prohibitive. To give an example of how quickly terrestrial laser scanners are evolving, one of the first ever terrestrial laser scanners was introduced in 1998 by Leica Geosystems and could capture 100 points per second. The Faro Focus 3D, introduced in 2012, can capture almost 1,000,000 points per second. The scanners used in the research in Dingle Bay, the Leica ScanStation and the Leica C10, are capable of capturing 4,000 and 50,000 points per second, respectively. With the ScanStation (which is currently the primary instrument being used - the C10 was only temporarily available), individual scans with parameters set as follows take about an hour:

Horizontal Field of View (FOV): approx. $180^{\circ}$

Vertical FOV:

Resolution:

Range: $90^{\circ}$ ( $+45^{\circ}$ to $-45^{\circ}$ from horizontal)

\section{$2.5 \mathrm{~cm}$}

$30 \mathrm{~m}$ 
With the $\mathrm{C} 10$, the time may be cut in half. Time spent scanning in registration targets (to register multiple scans to one common coordinate system) must also be factored in.

Additionally, in a coastal environment, it's especially important to consider the weather, the tides, and time spent getting to the field site if it's remote. In terms of the weather, some scanners are more resilient than others and may be robust to wind and (to some extent) light rain, although beware, as this may introduce unquantifiable error into the dataset.

\subsection{Working with large datasets}

Terrestrial laser scanned datasets are big. For example, the dataset described above contains in excess of 4 million points and takes up almost a half a gigabyte in space. For a single survey, which may contain 2 or 3 scans, this may not seem like a lot, but surveys in Dingle Bay take place at (somewhat) monthly intervals at two sites and will continue for a period spanning 2 years, generating around 100 datasets altogether. Storing, querying, and analysing these large datasets requires a reasonably powerful computer with plenty of storage space. Specialist software must also be purchased, as point clouds cannot be easily visualised or manipulated within GIS software and are usually too large to open in Microsoft Excel or Notepad. Software packages such as Leica Cyclone or Quick Terrain Modeler are available for visualising and editing point clouds, although licenses may be expensive. Finally, it should go without saying, but it is definitely worth investing in an external hard drive to backup TLS data.

\subsection{Classifying simple and complex scenes}

Digital surface models (DSMs) generated from terrestrial laser scanned data in vegetated dune environments represent surfaces that include both the bare ground and vegetation. Often the two must be separated to produce bare-Earth digital elevation models (DEMs) - we must "find the ground". Unlike aerial LIDAR systems, most groundbased laser scanners do not record multiple returns, therefore common filtering algorithms associated with vegetation removal from airborne LiDAR data, such as those proposed by Raber et al. (2002), Sithole and Vosselman (2004) or Kobler (2007), are not appropriate removing vegetation from terrestrial laser scanned data.

A handful of tools are available for filtering (removing unwanted information) and classifying (extracting features) TLS point cloud data. These include: lowest points analysis (Applied Imagery, 2009; Leica Geosystems, 2011), the use of reflected laser intensity to differentiate features from one another (Franceschi et al., 2009; Guarnieri et al., 2009), and classification using geometrical parameters (Hug et al., 2004; Brodu and Lague, 2012) and RGB imagery (Lichti, 2005). Depending on the complexity of the scene, some are more appropriate than others. An example of filtering using reflected laser intensity is shown in fig. 8. Intensity values represent the ratio of the strength of reflected light to that of emitted light and are proportional to the reflectance of the target at the specific wavelength of the incident laser. Different materials return different reflectance values, and thus intensity values may be used to differentiate between land cover types over a scanned area (Chust et al., 2008). There are, however, many factors which influence intensity, including surface roughness, geometry of acquisition (eg. distance from scanner, angle of incidence), surface moisture content, atmospheric dispersion, and even the instrument used (Lichti and Harvey, 2002; Jensen, 2009; Kaasalainen et al., 2011). While this complicates using intensity to classify several different land cover types (complex scenes), dune environments usually have only two basic land cover types, bare sand and vegetation. Assuming that this is true, and the two have significantly different intensities, it is expected that the intensity distribution of TLS point clouds from vegetated coastal dunes would be bimodal, with one peak representing vegetation and the other representing the bare surface (fig. 8). For more complex scenes, analyses based on geometrical parameters and RGB imagery may be more appropriate.

A more common filtering tool is lowest points analysis. In their study on changes in sediment and vegetation volumes after Hurricane Ike, Feagin et al. (2012) used this analysis to separate vegetation from the ground surface. With this method, the scanned surface is divided into a grid. Within each grid cell, all points but that with the lowest $z$-value are removed, and the remaining points on the grid are interpolated. Essentially, the analysis assumes that the point with the lowest $z$-value must be the ground. This, however, may not always be the case and is subject to both errors of omission (points excluded that are representative of the ground surface) and errors of commission 
(points included that are not representative of the ground surface). An evaluation of its effectiveness at representing the bare ground surface (ie. from ground truthing) was not reported by Feagin et al. (2012). Such an evaluation, regardless of the method chosen, is of critical importance if the purpose of the analysis is to compute volumetric change between surveys because if digital surface models are not, in fact, representing the surface under investigation well, then some error will be introduced into calculations of change between surfaces. This type of error may be especially significant in vegetated dune environments. An evaluation of the relative appropriateness of each of the tools available, based on data from one of the Dingle Bay sites, is currently underway.

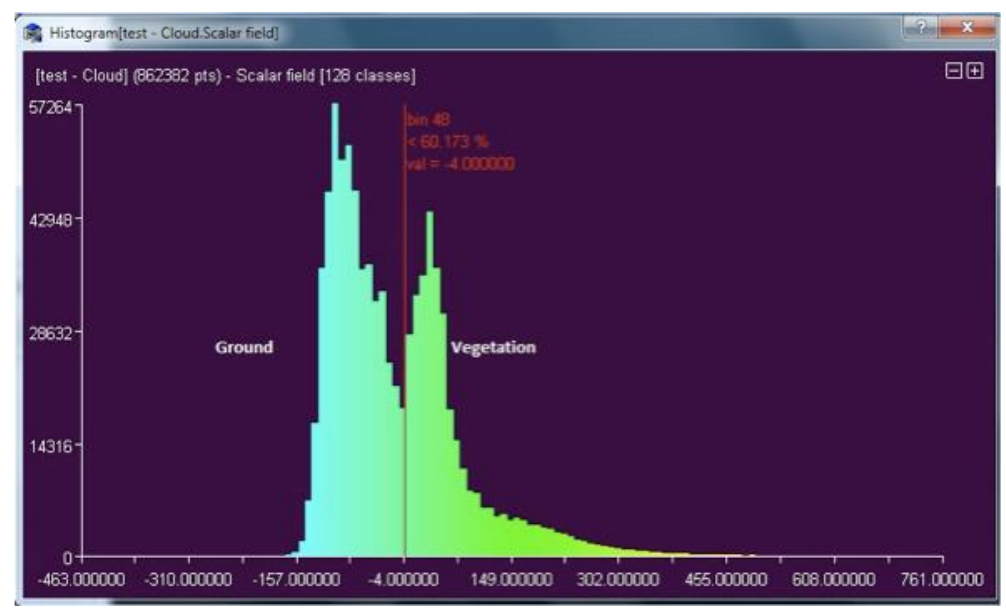

Figure 8 (a.): Intensity distribution for a small section of a vegetated foredune at Rossbeigh, Co. Kerry, Ireland.

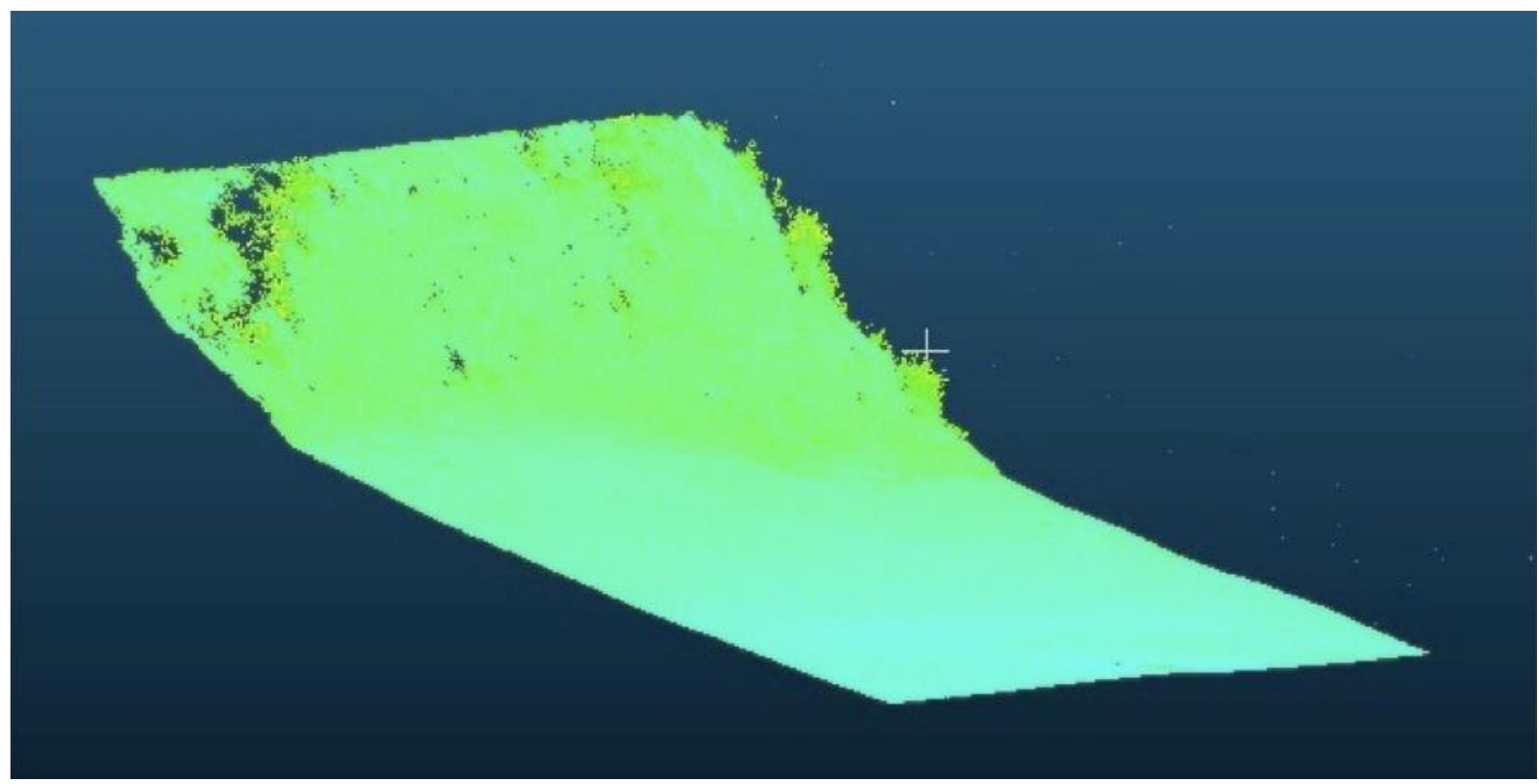

Figure 8 (b.): Intensity distribution for a small section of a vegetated foredune at Rossbeigh, Co. Kerry, Ireland. 


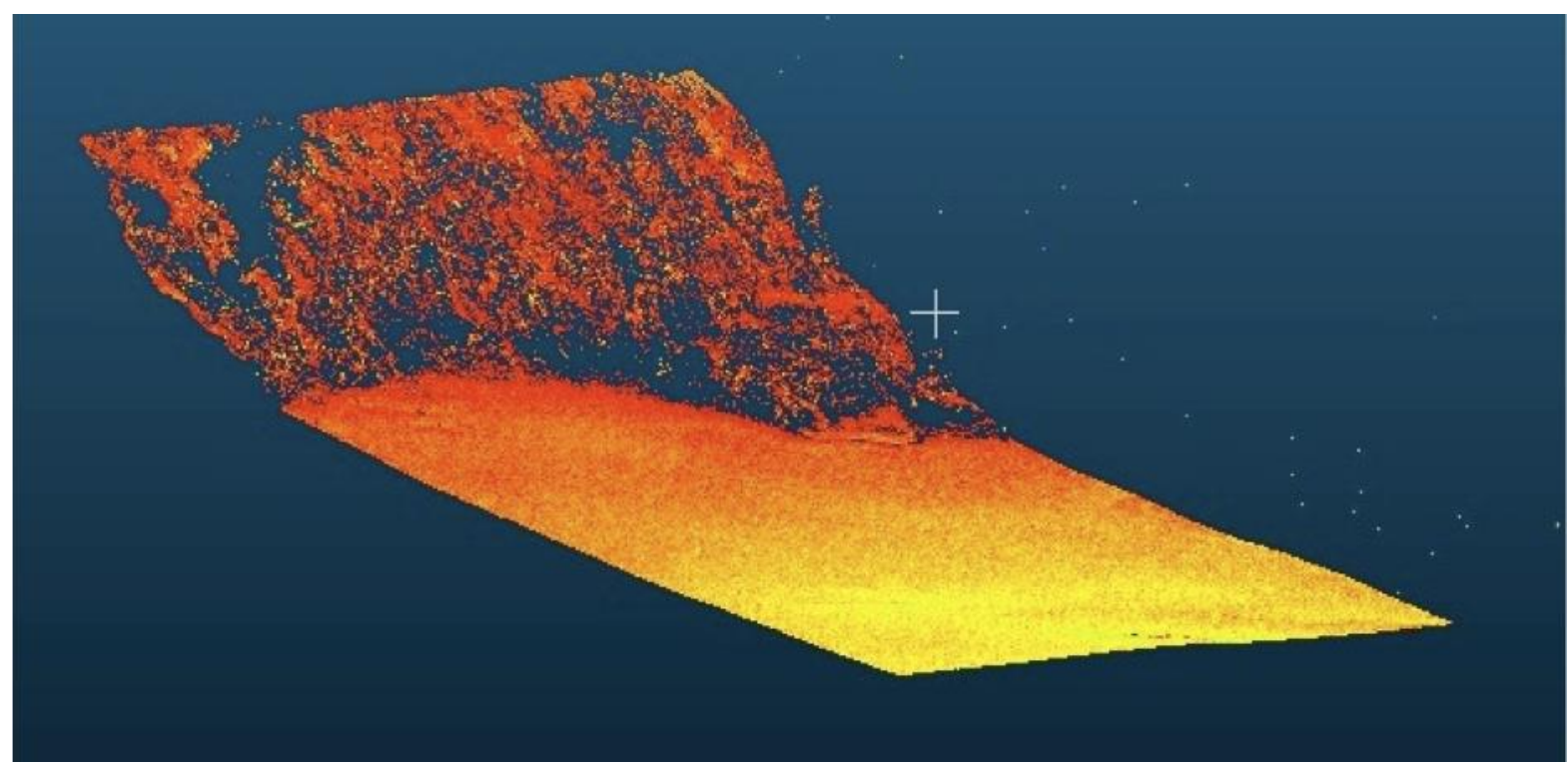

Figure 8 (c.): Assuming the ground and vegetation are the only two land cover types and the two have significantly different intensities, the peak on the left should represent the points on the ground surface and the peak on the right should represent vegetation points. If the vegetation points are filtered out, we are left with the surface shown in. In this case, $40 \%$ of the points have been deemed to represent vegetation and were thus removed.

\subsection{Analysing multi-temporal datasets}

Often coastal researchers are interested in analyzing multiple topographic datasets over time to quantify volumetric change between datasets and to identify spatial variability in elevation change across the study area. When this is the case, it is important to consider how scans may be accurately registered to one common coordinate system. Georeferencing TLS point clouds using GPS is not recommended for scans acquired at resolutions of less than $10 \mathrm{~cm}$ spacing because the precision of the scanner usually exceeds the resolution of the GPS (Bellian et al., 2005). As the research being conducted in Dingle Bay is concerned with micro-scale morphologic change, it was necessary to identify a way of registering scans that would allow for maximum registration accuracy (on the order of $\mathrm{mm}$ to $\mathrm{cm}$ ) to be achieved. Initially, five wooden posts with steel nail heads protruding approximately $5 \mathrm{~cm}$ out of the tops of the posts were installed at each field site. The nail heads acted as registration markers, which could be easily identified within the scans (fig. 10) and tagged as markers. The position and number of stationary markers is important. A minimum of three markers is required to register scans, but at least five should be present. At one of the Dingle Bay field sites, additional iron rods had to be installed because rapid erosion became a problem and two of the posts disappeared. The markers should also encircle the entire area to be analysed, as RMS error of registration can only be guaranteed within this area. Once the markers are identified and tagged in the cloud, all subsequent scans can be registered to the coordinate system of the first scan and viewed on top of one another. Figures 11 and 12 show changes in the position of the dune surface and beach elevation at Rossbeigh, Co. Kerry. An evaluation of volumetric change at the site will begin following identification of appropriate ground finding tools. The next challenge will be choosing an interpolation method to generate DEMs. 


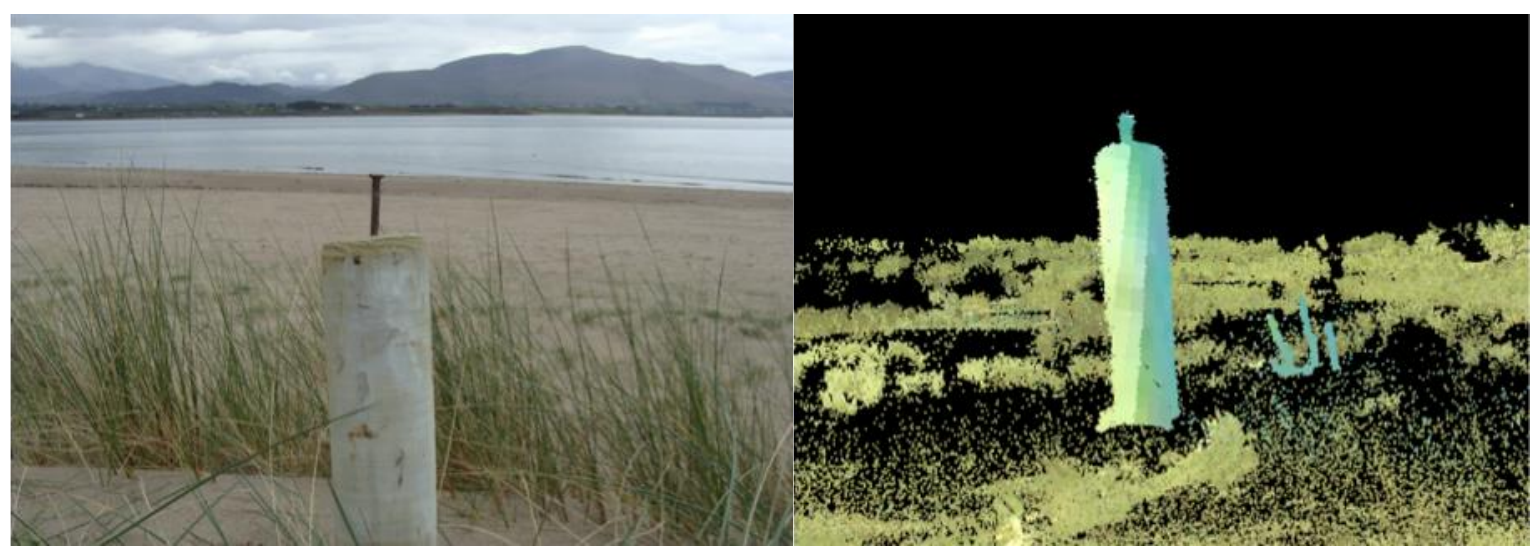

Figure 10 Photo (left) and scan (right) of one of the five wooden posts acting as a registration marker at the Inch field site. The nails at the top of the posts act as control points for registering successive monthly scans to one common coordinate system.

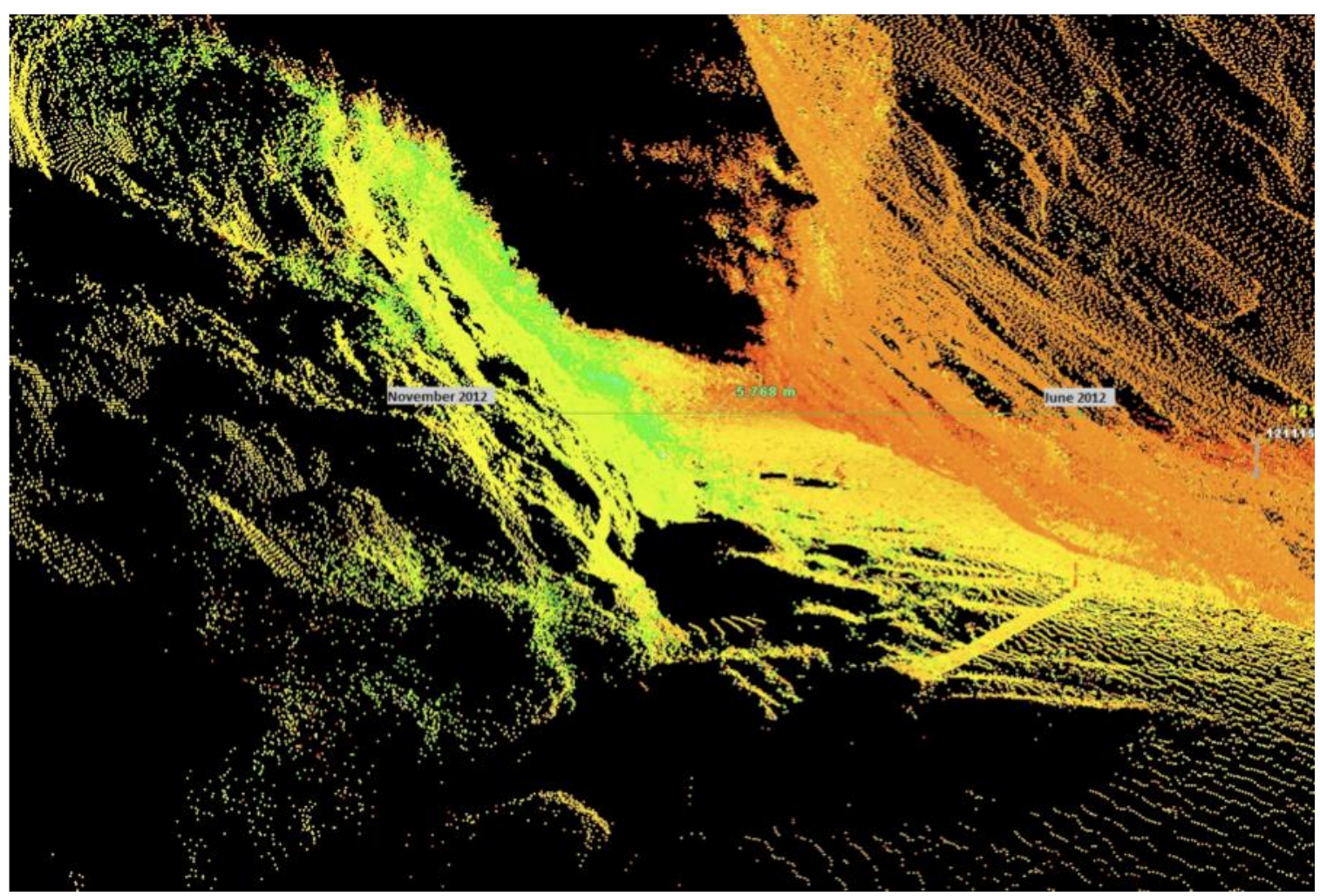

Figure 11 Difference in foredune surface from June (right) to November (left) 2012 at Rossbeigh, Co. Kerry. In this area, the foredune has receded by more than $5.5 \mathrm{~m}$. 


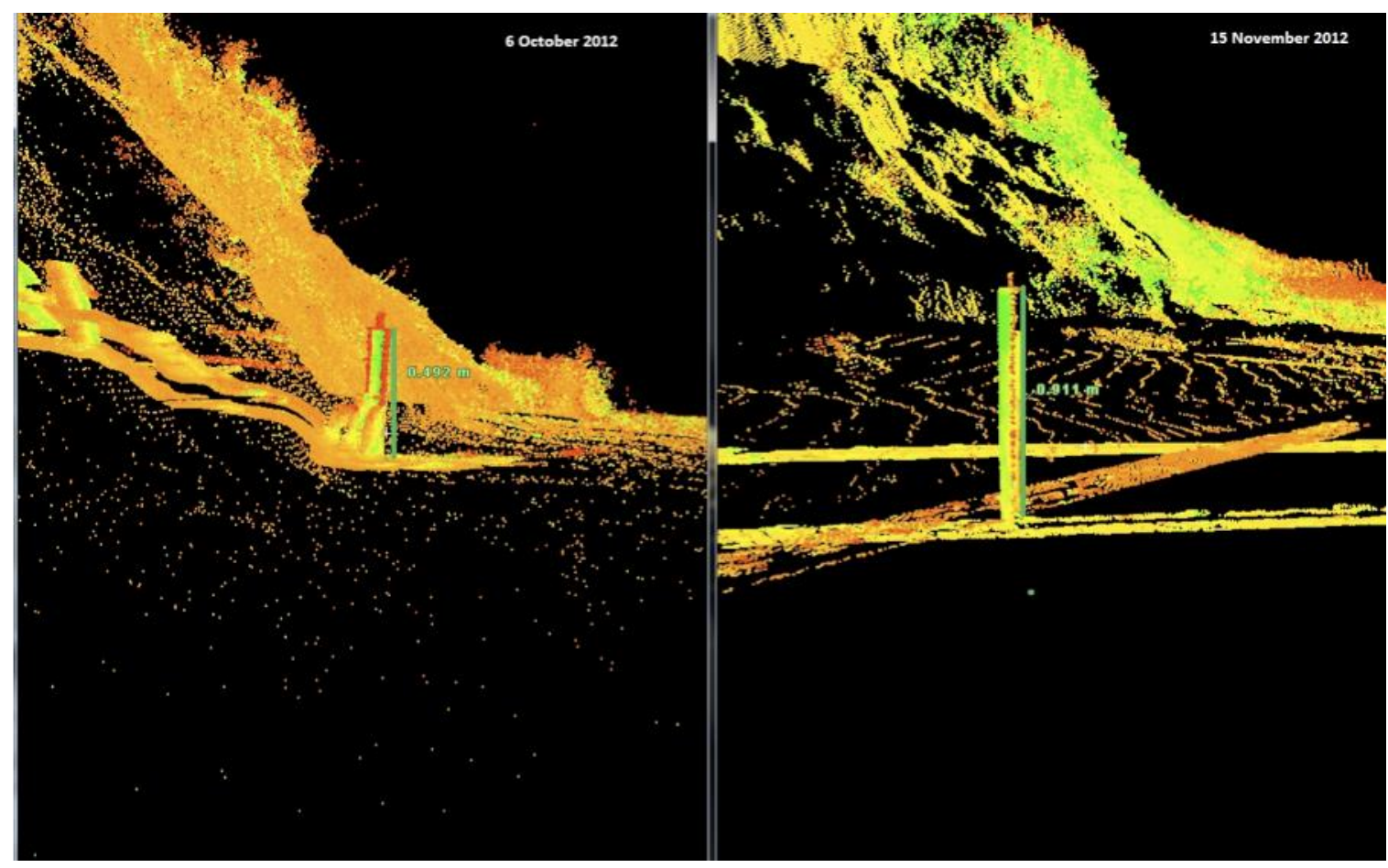

Figure 12: The difference in elevation of the beach surface between 6 October and 15 November 2012 could be identified from the difference in height of one of the wooden posts at Rossbeigh, Co. Kerry. The elevation of the beach over this time lowered by more than $\mathbf{4 0}$ $\mathrm{cm}$.

\section{Conclusion}

Terrestrial laser scanning is an exciting new approach to coastal monitoring with great potential in coastal research. While significant challenges remain, the increasing presence of TLS in coastal literature provides the foundations upon which these challenges can be overcome. By providing datasets that can improve our understanding of coastal processes, TLS is assisting in more efficient and proactive management of our coastal resource.

Ali, I., Braun, A., Sideris, M. G. and Anonymous 2011. Detecting morphological change on Galveston Island with airborne and terrestrial lidar. Abstracts with Programs - Geological Society of America. Geological Society of America (GSA).

Applied Imagery 2009. Quick Terrain Modeller. 7.0.0 ed. Silver Spring, MD: Johns Hopkins University Applied Physics Laboratory.

Bellian, J., Kerans, C. and Jennette, D. 2005. Digital outcrop models: applications of terrestrial scanning lidar technology in stratigraphic modeling. Journal of Sedimentary Research, 75, pp. 166-176.

Brock, J. and Purkis, S. 2009. The Emerging Role of Lidar Remote Sensing in Coastal Research and Resource Management. Journal of Coastal Research, 1-5.

Brodu, N. and Lague, D. 2012. 3D terrestrial lidar data classification of complex natural scenes using a multi-scale dimensionality criterion: Applications in geomorphology. ISPRS Journal of Photogrammetry and Remote Sensing, 68, pp.121-134.

Buckley, S. J., Howell, J., Enge, H. and Kurz, T. 2008. Terrestrial laser scanning in geology: data acquisition, processing and accuracy considerations. Journal of the Geological Society, 165, pp.625-638.

Chust, G., Galparsoro, I., Borja, Á., Franco, J. and Uriarte, A. 2008. Coastal and estuarine habitat mapping, using LIDAR height and intensity and multi-spectral imagery. Estuarine, Coastal and Shelf Science, 78, pp.633-643.

Coyne, M. A., Fletcher, C. H. and Richmond, B. M. 1999. Mapping Coastal Erosion Hazard Areas in Hawaii: Observations and Errors. Journal of Coastal Research, 28, pp.171-184. 
Dunning, S., Massey, C. and Rosser, N. 2009. Structural and geomorphological features of landslides in the Bhutan Himalaya derived from Terrestrial Laser Scanning. Geomorphology, 103, pp.17-29.

Feagin, R. A., Williams, A. M., Popescu, S., Stukey, J. and Washington-Allen, R. A. 2012. The Use of Terrestrial Laser Scanning (TLS) in Dune Ecosystems: The Lessons Learned. Journal of Coastal Research, DOI: 10.2112/JCOASTRES-D11-00223.

Franceschi, M., Teza, G., Preto, N., Pesci, A., Galgaro, A. and Girardi, S. 2009. Discrimination between marls and limestones using intensity data from terrestrial laser scanner. ISPRS Journal of Photogrammetry and Remote Sensing, 64, pp.522-528.

Gesch, D. B. 2009. Analysis of Lidar Elevation Data for Improved Identification and Delineation of Lands Vulnerable to Sea-Level Rise. Journal of Coastal Research, 53, pp. 49-58.

Guarnieri, A., Vettore, A., Pirotti, F., Menenti, M. and Marani, M. 2009. Retrieval of small-relief marsh morphology from Terrestrial Laser Scanner, optimal spatial filtering, and laser return intensity. Geomorphology, 113, 12-20.

Heritage, G. L. and Large, A. R. G. 2009. Laser scanning for the environmental sciences, UK: Blackwell Pub.

Hug, C., Krzystek, P. and Fuchs, W. 2004. Advanced lidar data processing with LasTools. International Archives of Photogrammetry and Remote Sensing, 35, pp. 832-837.

Jensen, J. R. 2009. Remote Sensing of the Environment: An Earth Resource Perspective, India: Pearson Education. Kaasalainen, S., Jaakkola, A., Kaasalainen, M., Krooks, A. and Kukko, A. 2011. Analysis of Incidence Angle and Distance Effects on Terrestrial Laser Scanner Intensity: Search for Correction Methods. Remote Sensing, 3, pp.22072221.

Kobler, A., Pfeifer, N., Ogrinc, P., Todorovski, L., Oštir, K. and Džeroski, S. 2007. Repetitive interpolation: A robust algorithm for DTM generation from Aerial Laser Scanner Data in forested terrain. Remote Sensing of Environment, 108, pp.9-23.

Leica Geosystems 2011. Cyclone II Topo. 2.0.188.0 ed. Switzerland: Heerbrugg.

Lichti, D., Gordon, S. and Tipdecho, T. 2005. Error Models and Propagation in Directly Georeferenced Terrestrial Laser Scanner Networks. Journal of Surveying Engineering, 131, pp.135-142.

Lichti, D. and Harvey, B. 2002. The effects of reflecting surface material properties on time-of-flight laser scanner measurements. Symposium on Geospatial Theory, Processing and Applications. Ottawa.

Lichti, D. D. 2005. Spectral Filtering and Classification of Terrestrial Laser Scanner Point Clouds. The Photogrammetric Record, 20, pp.218-240.

Lim, M., Petley, D. N., Rosser, N. J., Allison, R. J., Long, A. J. and Pybus, D. 2005. Combined Digital Photogrammetry and Time-of-Flight Laser Scanning for Monitoring Cliff Evolution. The Photogrammetric Record, 20, pp.109-129.

Lindenbergh, R. C., Soudarissanane, S. S., De Vries, S., Gorte, B. G. H. and De Schipper, M. A. 2011. Aeolian Beach Sand Transport Monitored by Terrestrial Laser Scanning. The Photogrammetric Record, 26, pp.384-399.

Meehl, G. A., Stocker, T. F., Collins, W., Friedlingstein, P., Gaye, A., Gregory, J., Kitoh, A., Knutti, R. and Co-authors 2007. Surface and atmospheric climate change. In: Solomon, S., Qin, D., Manning, M., Chen, Z., Marquis, M., Averyt, K. B., Tignor, M. and Miller, H. L., eds., Climate Change 2007: The Physical Science Basis. Contribution of Working Group I to the Fourth Assessment Report of the Intergovernmental Panel on Climate Change. Cambridge: CUP.

Nagihara, S., Mulligan, K. R. and Xiong, W. 2004. Use of a three-dimensional laser scanner to digitally capture the topography of sand dunes in high spatial resolution. Earth Surface Processes and Landforms, 29, pp.391-398.

Nield, J. M. and Wiggs, G. F. S. 2011. The application of terrestrial laser scanning to aeolian saltation cloud measurement and its response to changing surface moisture. Earth Surface Processes and Landforms, 36, pp.273278. 
Nield, J. M., Wiggs, G. F. S. and Squirrell, R. S. 2011. Aeolian sand strip mobility and protodune development on a drying beach: examining surface moisture and surface roughness patterns measured by terrestrial laser scanning. Earth Surface Processes and Landforms, 36, pp.513-522.

Olsen, M. J. 2009. Methodology for assessing coastal change using terrestrial laser scanning. Ph.D. 3358639, University of California, San Diego.

Parry, M. L., Canziani, O. F., Palutikof, J. P., van der Linden, P. J. and Hanson, C. E. 2007. Climate change 2007: impacts, adaptation and vulnerability. Contribution of Working Group II to the Fourth Assessment Report of the IPCC. Cambridge: CUP.

Pietro, L. S., O'Neal, M. A. and Puleo, J. A. 2008. Developing Terrestrial-LIDAR-Based Digital Elevation Models for Monitoring Beach Nourishment Performance. Journal of Coastal Research, 24, pp.1555-1564.

Rabenhold, C. 2012. Coastal Hazards [Online]. National Oceanic and Atmospheric Administration. Available: http://coastalmanagement.noaa.gov/hazards.html [Accessed 2012].

Raber, G. T., Jensen, J. R., Schill, S. R. and Schuckman, K. 2002. Creation of digital terrain models using an adaptive lidar vegetation point removal process. PE \& RS-Photogrammetric Engineering \& Remote Sensing, 68, pp.1307-1315.

Rosser, N., Petley, D., Lim, M., Dunning, S. and Allison, R. 2005. Terrestrial laser scanning for monitoring the process of hard rock coastal cliff erosion. Quarterly Journal of Engineering Geology \& Hydrogeology, 38, pp.363.

Sithole, G. and Vosselman, G. 2004. Experimental comparison of filter algorithms for bare-Earth extraction from airborne laser scanning point clouds. ISPRS Journal of Photogrammetry and Remote Sensing, 59, pp.85-101.

Soeder, E. and Jenkins, M. G. Year. Coastal Applications for High Definition Survey/Laser Scanning Technology. In: Proceedings of the Florida Shore \& Beach Preservation Association: National Conference on Beach Preservation Technology, 2006 Sarasota, FL. FSBPA.

Soudarissanane, S., Lindenbergh, R., Menenti, M. and Teunissen, P. 2011. Scanning geometry: Influencing factor on the quality of terrestrial laser scanning points. ISPRS Journal of Photogrammetry and Remote Sensing, 66, pp.389399.

Travelletti, J., Oppikofer, T., Delacourt, C., Malet, J. and Jaboyedoff, M. 2008. Monitoring landslide displacements during a controlled rain experiment using a long-range terrestrial laser scanning (TLS). The International Archives of Photogrammetry, Remote Sensing and Spatial Information Sciences, 38, pp.485-490.

Trenberth, K. E., Jones, P. D., Ambenje, P. G., Bojariu, R., Easterling, D. R., Tank, A. M. G. K., Parker, D. E., Renwick, J. A. and Co-authors 2007. Surface and atmospheric climate change. In: Solomon, S., Qin, D., Manning, M., Chen, Z., Marquis, M., Averyt, K. B., Tignor, M. and Miller, H. L., eds., Climate Change 2007: The Physical Science Basis. Contribution of Working Group I to the Fourth Assessment Report of the Intergovernmental Panel on Climate Change. Cambridge: CUP.

van Gaalen, J. F., Kruse, S. E., Coco, G., Collins, L. and Doering, T. 2011. Observations of beach cusp evolution at Melbourne Beach, Florida, USA. Geomorphology, 129, pp. 131-140.

\section{Acknowledgements}

The author would like to thank Prof. Robert Devoy, Dr. Fiona Cawkwell, and Jeremy Gault for their continued support and encouragement; Mary Murphy and Roisin Murphy for their technical assistance; Andrew O'Callaghan and John Kennedy for their assistance in the field; and the Department of Geography at University College Cork for funding part of this research. 


\section{Biography}

Sarah Kandrot is a second year PhD researcher in the Geography Department at University College Cork studying under the direction of Prof. Robert Devoy, Dr. Fiona Cawkwell, and Jeremy Gault. A graduate of Boston University, she received her BA in Earth Science in 2009. At UCC, she completed a Higher Diploma in Geography with first class honours before earning a Masters in Coastal Zone Management and Geographical Information Systems (GIS), also with first class honours. Her PhD research involves investigating dune morphodynamics using terrestrial laser scanning (TLS). Her main research interests are in coastal morphodynamics, marine environments, climate change and paleo-environments, sea-level rise, the impacts of climate change on coastal and marine environments, sedimentology/stratigraphy, terrestrial laser scanning, and geographical information systems.

\section{Contact}

Sarah M. Kandrot, Department of Geography, University College Cork, Cork, Ireland.

109222085@umail.ucc.ie 